\title{
Imidazole-doped nanocrystalline cellulose solid proton conductor: synthesis, thermal properties, and conductivity
}

\author{
J. Tritt-Goc $\cdot$ I. Jankowska $\cdot$ K. Pogorzelec-Glaser $\cdot$ R. Pankiewicz $・$ \\ P. Lawniczak
}

Received: 21 July 2017 / Accepted: 3 November 2017/Published online: 20 November 2017

(C) The Author(s) 2017. This article is an open access publication

\begin{abstract}
A new proton conducting material with a possible application as a membrane in fuel cells is synthesized. It is formed by nanocrystalline cellulose (NCC) doped with a different concentration of the imidazole molecules (Im) used as "dry" conducting species. The nanocomposites (NCC-Im) are obtained in the form of films. Their chemical composition, thermal properties, and the electric conductivity are determined by elementary and thermogravimetric analysis, differential scanning calorimetry and impedance spectroscopy methods, respectively. The nanocomposite (1.7NCC-Im) with the highest concentration of imidazole i.e. one Im per 1.7 glucose unit shows the highest electrical conductivity equal to
\end{abstract}

\footnotetext{
J. Tritt-Goc $(\bowtie) \cdot$ I. Jankowska · K. Pogorzelec-Glaser ·

P. Ławniczak

Institute of Molecular Physics, Polish Academy of

Sciences, M. Smoluchowskiego 17, 60-179 Poznań,

Poland

e-mail: jtg@ifmpan.poznan.pl

I. Jankowska

e-mail: iga.a.jankowska@gmail.com

K. Pogorzelec-Glaser

e-mail: kglaser@ifmpan.poznan.pl

P. Ławniczak

e-mail: pawel@lawniczak.ifmpan.poznan.pl

R. Pankiewicz

Faculty of Chemistry, Adam Mickiewicz University,

Umultowska 89b, 61-614 Poznań, Poland

e-mail: radek@px.pl
}

$2.7 \times 10^{-2} \mathrm{~S} / \mathrm{m}$ at $140{ }^{\circ} \mathrm{C}$. This value is about five orders of magnitude higher than that of the pure NCC film at this same temperature. The important feature is that it is obtained for nanocomposite under anhydrous conditions.

Keywords Nanocrystalline cellulose · Imidazole · Synthesis of nanocomposites - Thermal properties . Impedance spectroscopy · Proton conductivity

\section{Introduction}

The development of inexpensive, easy in production, flexible, solid-state, and sustainable energy producing materials is essential to meet a predicted increase in energy consumption in today's society and protect the environment. Such materials can find application in a variety of electrochemical devices including fuel cells which are of special interest because they permit clean and direct conversion from the chemical to electrical energy (Devanathan 2008; Sharaf and Orhan 2013; Zhang et al. 2015; Hu et al. 2017). A particularly important task is development of proton exchange membrane (PEM) as it allows transportation of protons from anode to cathode and plays a role of a separator between the two electrodes (Devanathan 2008; Sharaf and Orhan 2013; Zhang et al. 2015; Hu et al. 2017; Kreuer 1997; Schuster and Meyer 2003). A great challenge is to find an appropriate substance 
which would be able to fulfill both functions at the same time. Several types of polymeric materials with high proton conductivity have been developed (Zhang et al. 2015; Hu et al. 2017; Gasteiger et al. 2005; Curtin et al. 2004; Song and Tsiakaras 2006; Xing and Savadogo 2000; Celik et al. 2012; Savinell et al. 1994; Li et al. 2009; Mauritz and Moore 2004; Gierke et al. 1981; Scott et al. 2014) including polymers containing poly(tetrafluoroethylene) backbones with different anion-terminated side chains, such as Nafion (Devanathan 2008; Sharaf and Orhan 2013; Mauritz and Moore 2004; Gierke et al. 1981). However, these materials exhibited high proton conductivity only in hydrated conditions, which limits the operating temperature of the device to about $90{ }^{\circ} \mathrm{C}$. Furthermore, Nafion which is most commonly used as PEM in fuel cells is relatively expensive and its production is a challenge.

Consequently, the search for cheaper, easy in production, flexible, solid-state, and environmentally friendly compounds for membranes that can operate under anhydrous conditions in the intermediate temperature range, is continued. The proton conducting separator materials with the above mentioned properties are widely considered to be one of the keys to further progress in PEM fuel cell technology (Scott et al. 2014).

A higher membrane operation temperature may be obtained by substituting water present in conventional acid membranes, by another proton solvent with a higher boiling point. However, a general disadvantage of other proton solvents is their volatility. Thus, the higher temperature application requires their immobilization in polymer matrix where a high local mobility of proton solvent and the protonic charge carriers therein still have to be guaranteed. In this respect, biopolymer carrier compounds such as cellulose doped with the electro active heterocyclic molecules containing nitrogen (imidazole and its derivatives) are highly interesting (Smolarkiewicz et al. 2015, 2016; Zhao et al. 2016). The heterocycles are attractive due to their amphoteric nature, high thermal stability, formation of a hydrogen bonding network similar to that found in water, and a high degree of self-dissociation, which is beneficial for the proton transfer (Kreuer et al. 1998). Replacement of water by heterocyclic molecules as "dry" conducting species is expected to allow conductivity at above $100{ }^{\circ} \mathrm{C}$. Cellulose is a natural renewable material and the most abundant polymer on Earth. Moreover, development of nanotechnology allowed the creation of one-dimensional nanoscale nanocellulose (Dufresne 2013; Borjesson and Westmann 2015; Peng et al. 2011; Miao and Hamad 2013; Mariano et al. 2014; Siqueira et al. 2010; Moon et al. 2011; Anglès and Dufresne 2000).

In our previous studies, we successfully synthesized a composite of microcrystalline cellulose doped with imidazole (Cell-Im) and obtained proton conductive composite which exhibited conductivity by four orders of magnitude higher than a pure cellulose sample and equal to $2.0 \times 10^{-4} \mathrm{~S} / \mathrm{m}$ at $160{ }^{\circ} \mathrm{C}$ (Smolarkiewicz et al. 2015, 2016). The Cell-Im is stable in the temperature range from 110 to about $160{ }^{\circ} \mathrm{C}$. Usually, this type of material operates in a humidified environment therefore, the result obtained was unique. In the synthesis, we used unmodified microcrystalline cellulose which is insoluble in most solvents, also in chloroform applied for the preparation of the studied composites, and thus forms a suspension. This limited the imidazole-cellulose ratio because the imidazole molecules are only bonded to the hydroxyl groups of cellulose on the cellulose grains' surfaces. Therefore, we were able to synthesize the composite based on the microcrystalline cellulose with the highest concentration of imidazole in the final product of only $1.0 \mathrm{mM} / \mathrm{g}$, corresponding to the molar cellulose-glucose unit/imidazole ratio of about 5.0.

Here, we proposed further development of this type of the proton conducting composite but including nanocrystalline cellulose (NCC) as the matrix carrier doped with the imidazole molecules. The cellulose nanocrystal's properties, including high surface area, makes it an ideal replacement for microcrystalline cellulose (Dufresne 2013). Nanosize cellulose can be extracted from almost any cellulosic material by green technology. Most common sources are plants, animals (tunicates), bacteria, and algae. In all sources, the cellulose polymer is composed of a chain of glucose units linked through $\beta-1,4$ glycosidic bonds (O'Sullivan 1997). According to different preparation methods (mechanical, oxidation and hydrolysis method), two types of nanocellulose: cellulose nanofibres (CNF) and cellulose nanocrystals (NCC) can be produced (Borjesson and Westmann 2015; Peng et al. 2011; Siqueira et al. 2010; Moon et al. 2011). Cellulose nanocrystals are obtained by a controlled hydrolysis treatment with strong acid which when applied to 
cellulosic fibers allows dissolution of their amorphous domains and thus longitudinal cutting of the microfibres. The fibers are separated from each other by ultrasound or sonication. NCCs are rod-shaped particles and are obtained as an aqueous suspension. Their geometrical dimensions depend on the origin of the cellulose substrate and hydrolysis conditions. The average lengths varies from 100 to $600 \mathrm{~nm}$ to over several $\mu \mathrm{m}$ and the width varies in the range 2-20 nm (Borjesson and Westmann 2015; Peng et al. 2011; Siqueira et al. 2010; Moon et al. 2011). Nanocrystalline cellulose represents a new class of nanomaterials. It is natural, biodegradable and biocompatible. Nanocrystalline cellulose, when compared to microcrystalline cellulose, shows many advantages, such as nanoscale dimension, high aspect ratio and high surface area, high strength, high thermal stability, lightweight, higher water binding capability, and opportunities for chemical modification (surface $\mathrm{OH})$. Thanks to the above physicochemical properties, the nanocrystalline cellulose is called the "material of the future" and is an object of high interest to researchers and manufacturers.

Previously reported results have shown that nanocellulose when combined with the conducting electroactive materials, formed electroconductive composites with different microscale and structural characteristics (Mariano et al. 2014; Siqueira et al. 2010; Moon et al. 2011; Anglès et al. 2000; Pandey et al. 2012). The conductive materials include a conductive polymer (e.g., polypyrrole, polyaniline), metal oxide (manganese dioxide-titanium dioxide zinc oxide) and carbon materials (e.g., carbon nanotubes, graphene). The conducting polymer/nanocellulose composites are mainly used in electrochromic devices, electrochemical sensors, and super capacitors. Electroconductive composites of nanocellulose with carbon nanotubes and graphene could be used as a flexible electrodes for flexible batteries and flexible supercapacitors, whereas those formed with metal oxide nanoparticles can be possibly used for photovoltaic materials and solar cells. Such a rapid development of nanocellulose in a variety of fields is related to its unique properties including also its ability to form films and gels. The first report on pure nanocellulose membranes for fuel cells in which the proton conductivity was observed above $100{ }^{\circ} \mathrm{C}$ was published by Bayer (Bayer et al. 2016). They studied the proton conductivity of pure cellulose nanocrystals and pure cellulose nanofibers over a wide temperature range and humidity. The conductivity of NCC is equal to $4.6 \times 10^{-1} \mathrm{~S} / \mathrm{m}$ at $120^{\circ} \mathrm{C}$ whereas that of $\mathrm{CNF}$ reaches $5.0 \times 10^{-3} \mathrm{~S} / \mathrm{m}$ at $100{ }^{\circ} \mathrm{C}$ and drops above this temperature to $1.0 \times 10^{-3} \mathrm{~S} / \mathrm{m}$. In both cases, the conductivity strongly depends on humidity because water protons are the conductive species.

In this paper, we present results of a study of the nanocellulose composites functionalized with imidazole (NCC-Im). The modification of NCC surfaces with heterocycles molecules containing nitrogen is a pioneering element of our studies not found in literature to the best of our knowledge. The replacement of water by imidazole and cellulose by nanocellulose results in the nanocomposites characterized by the conductivity in the intermediate temperature range and under anhydrous conditions. Such composites can be desirable for various electrochemical devices and relevant in modern material science. We reported on the synthesis of nanocomposites with three different concentrations of imidazole, their thermal, and conductivity properties. The composites were prepared in the form of films.

\section{Materials}

NCC was purchased in the form of a stable suspension of nanocrystals, in the concentration of $7.4 \% \mathrm{w} / \mathrm{w}$ from Blue Goose Bio refineries Inc from Canada. It was obtained in the process over enzymatic catalysts to ensure no presence of acidic groups or foreign elements such as sulfur, nitrogen or chlorates. Imidazole (Im) and anhydrous chloroform, $\geq 99 \%$, were obtained from Sigma-Aldrich Company. According to the specification, the crystallinity index of NCC is $83 \%$, the crystal length is $100-150 \mathrm{~nm}$, the crystal diameter is $9-14 \mathrm{~nm}$, and the hydrodynamic diameter is $400 \mathrm{~nm}$.

\section{Synthesis of nanocomposites}

The NCC-Im nanocomposites were prepared according to the following procedure: a portion of $13.5 \mathrm{~g}$ of nanocellulose suspension ( $1 \mathrm{~g}$ dry mass) was diluted in $15 \mathrm{ml}$ of water on stirring with a fast rotating magnetic stirrer, for $30 \mathrm{~min}$ at $25^{\circ} \mathrm{C}$. Next, $20 \mathrm{ml}$ of a water solution of imidazole was added and the whole 
contents were subjected to vigorous stirring for $1 \mathrm{~h}$. After addition of $25 \mathrm{ml}$ of chloroform on intense shaking to remove unbound imidazole, the chloroform solution was separated. To remove all residues of the organic solvent, the water suspension was placed in a rotating vacuum evaporator at $25^{\circ} \mathrm{C}$ and the sample was concentrated to reach a half of its original volume. The milk-white suspension obtained was poured into the Petri dish and dried at room temperature under limited air flow. The final composites were in the form of a hard, colorless, semitransparent films of the thickness close to $0.1 \mathrm{~mm}$. Extending the stirring time of the substrate solutions to $2 \mathrm{~h}$ resulted in the increase in the content of imidazole in the composite.

\section{Methods}

Elementary analysis

Elemental analyzer, Vario EL III GmbH Germany, equipped with a standard $\mathrm{CHN}$ detector was used to analyze the synthesized three nanocomposites. The analysis was repeated three times with differences less than $0.2 \%$. The mass of each sample was $20 \mathrm{mg}$.

\section{Scanning electron microscopy}

Scanning electron microscopy (SEM) images of NCCIm film were taken with a Fei NovaSEM 650 microscope in vacuum better than $6 \times 10^{-4} \mathrm{~Pa}$ at room temperature.

\section{Thermogravimetric analysis}

Thermogravimetric analysis (TGA) measurements for pure and imidazole doped nanocellulose films were performed on a TGA4000 Perkin-Elmer instrument. The mass changes in the samples as a function of temperature and time were recorded at a heating rate of $10^{\circ} \mathrm{C} / \mathrm{min}$ in the temperature range from room temperature to $600{ }^{\circ} \mathrm{C}$ under air flow.

\section{Differential scanning calorimetry}

Differential scanning calorimetry (DSC) measurements were performed using NETZSCH DSC 200F3 calorimeter under helium atmosphere for pure NCC and NCC-Im- films, in the temperature range from 5 to
$250{ }^{\circ} \mathrm{C}$. The film samples of about $3 \mathrm{mg}$ in mass were placed in closed pans with a small hole punctured at the top. DSC scans were run on heating and cooling cycles with a scanning rate of $10{ }^{\circ} \mathrm{C} / \mathrm{min}$. During the first run the samples were heated from 5 to $110{ }^{\circ} \mathrm{C}$ at this temperature was maintained for about $20 \mathrm{~min}$ and next the samples were cooled down to $5{ }^{\circ} \mathrm{C}$. The second heating run was performed in the temperature range of $5-250{ }^{\circ} \mathrm{C}$.

\section{Electrical impedance spectroscopy}

A standard impedance spectroscopy method was applied to determine the dc electric conductivity of NCC and NCC-Im films. The complex impedance of these samples was measured using an Alpha-A HighPerformance Frequency Analyzer from Novo control $\mathrm{GmbH}$ in the frequency range from $1 \mathrm{~Hz}$ to $10 \mathrm{MHz}$ and with the voltage oscillations of $\pm 1 \mathrm{~V}$. The samples were prepared from film materials, which were coated with gold electrodes using a BAL-TEC SCD 050 Sputter Coater. Their complex impedance was measured during two heating cycles. The first heating cycle was performed in the temperature range from 0 to $110{ }^{\circ} \mathrm{C}$ then the samples were cooled to $0{ }^{\circ} \mathrm{C}$. Next, the second heating cycles were performed in the range from 0 to $220{ }^{\circ} \mathrm{C}$. The temperature was controlled using a Quatro Cryosystem with accuracy better than $\pm 0.01{ }^{\circ} \mathrm{C}$.

\section{Results and discussion}

\section{Characterization of NCC-Im composites}

The chemical composition of functionalized NCC composites was determined by elemental analysis which allows calculating the average percentage of carbon, hydrogen, and nitrogen atoms of studied samples. Imidazole content of the nanocomposites was calculated on the basis of the corresponding nitrogen and carbon data (see Table 1).

The sample labelled as $1.7 \mathrm{NCC}-\mathrm{Im}$ is characterized by the highest concentration of Im molecules, it contained one Im per 1.7 glucose unit. The content of imidazole in the other two composites is equal to one Im per 3.8 (3.8NCC-Im) and 5 (5NCC-Im) glucose unit. NCC is not dissolved into the chloroform used for the preparation of nanocomposites. Therefore, the 
Table 1 The chemical composition of synthetized NCC-Im samples determined by elementary analysis

\begin{tabular}{lllll}
\hline Sample & Carbon content $(\%)$ & Hydrogen content $(\%)$ & Nitrogen content $(\%)$ & $\begin{array}{l}\text { Number of glucose rings } \\
\text { per one Im molecule }\end{array}$ \\
\hline $5 \mathrm{NCC}-\mathrm{Im}$ & 43.23 & 6.74 & 2.67 & 5.80 \\
$3.8 \mathrm{NCCl}-\mathrm{Im}$ & 43.34 & 6.58 & 3.92 & 3.80 \\
$1.7 \mathrm{NCCl}-\mathrm{Im}$ & 43.31 & 6.46 & 7.71 & 1.68 \\
\hline
\end{tabular}

imidazole molecules are bonded only to the hydroxyl groups of the cellulose nanocrystals' surfaces. The surface morphology of the nanocomposites was studied by SEM and the results for 5NCC-Im nanocomposite film are illustrated in Fig. 1.

\section{Thermal properties}

The study of thermal properties (TGA, DSC) of any material is a dynamic phenomenological approach which allows investigation of its response to a variation in temperature and consequently, to evaluate its thermal stability and degradation profiles. For this reason, we employed these methods to study NCC composites. TGA thermograms show changes in mass of the studied sample during heating whereas their derivatives obtained by Derivative Thermogravimetric (DTG) analysis show changes in the slope which may not be well noticeable from the curve of TGA.

Figure 2 depicts TGA thermograms and the corresponding DTG curves of NCC-Im together with the analogous data for NCC, for comparison. The onset and endset temperatures, max temperature of the process and mass loss for all nanocomposites studied are presented in Table 2. The process of decomposition of NCC film displays three mass loss steps with maximum decomposition at about 212, 275 and $350{ }^{\circ} \mathrm{C}$. They are connected to the decomposition of the film (not observed for NCC powder), the structure of cellulose nanocrystals (breaking of hydrogen bonds between nanocrystals and between the glucose units in the cellulose chains) and the pyrolysis of cellulose, respectively (Szcześniak et al. 2008). In the degradation profile of NCC-Im (Fig. 2b), we also can easily distinguish the main mass loss peak at $350{ }^{\circ} \mathrm{C}$ which is slightly wider and shifted toward the lower temperature as compared to the corresponding peak of NCC film. We assumed that this peak reflects two mass loss steps observed in NCC film as separated peaks at 270 and $350{ }^{\circ} \mathrm{C}$. The second maximum decomposition temperature at around $225{ }^{\circ} \mathrm{C}$ observed in NCC-Im is associated with the loss of imidazole molecules as for microcrystalline Cell-Im composites. The boiling point of imidazole is equal to $256{ }^{\circ} \mathrm{C}$ but in the composites, the loss of imidazole molecules occurs at a lower temperature as shown for microcrystalline Cell-Im composites (Smolarkiewicz et al. 2015). For the samples with the higher concentration of imidazole, 3.8NCC-Im, and 1.7NCC-Im, an additional mass loss step with maximum decomposition at about $150{ }^{\circ} \mathrm{C}$ is well distinguished. This peak can be assigned to the strongly bonded water molecules but
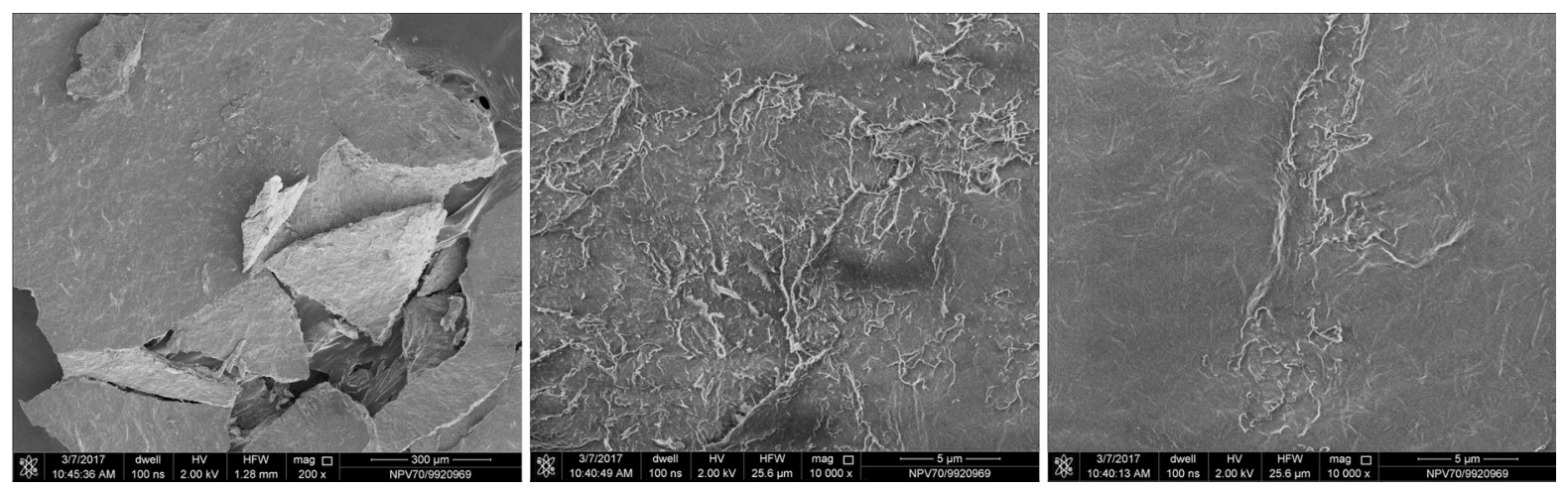

Fig. 1 SEM images of 5NCC-Im nanocomposite film. The scale bar in the first image corresponds to $300 \mu \mathrm{m}$ and in the next two to $5 \mu \mathrm{m}$ 

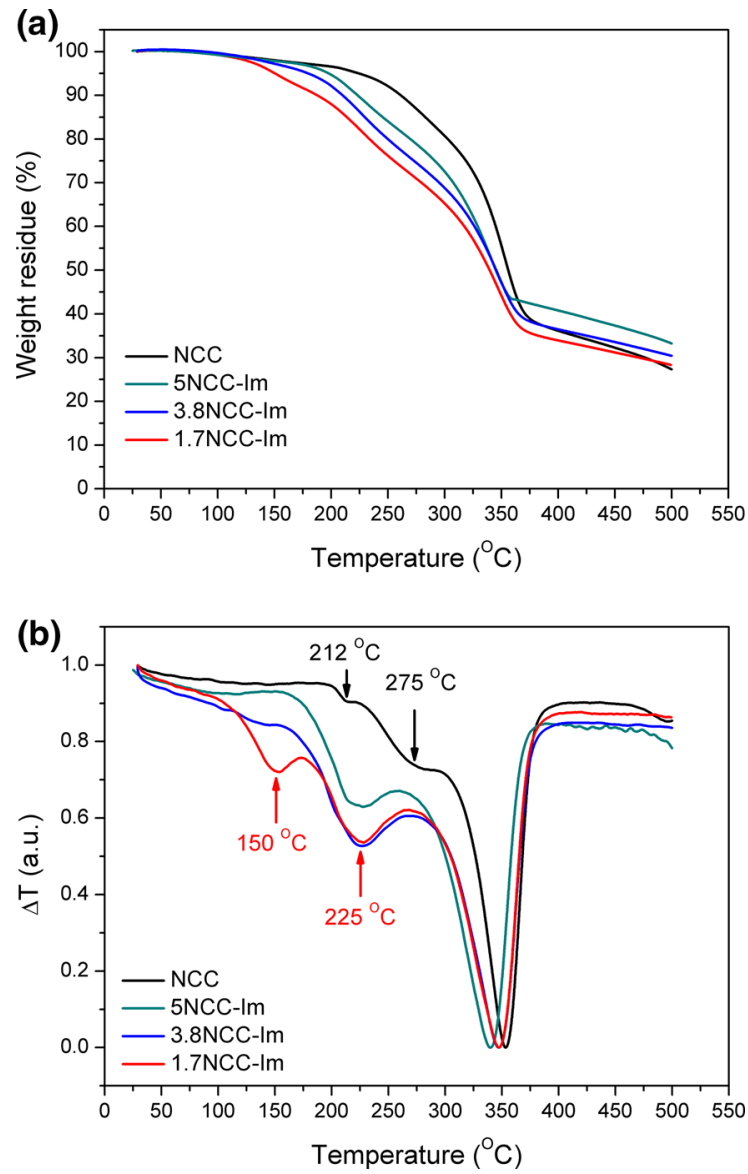

Fig. 2 TGA thermograms (a) and the corresponding derivatives DTG (b) of NCC and 5NCC-Im, 3.8NCC-Im, and $1.7 \mathrm{NCC}-\mathrm{Im}$ nanocomposites films recorded with a heating rate of $10^{\circ} \mathrm{C} / \mathrm{min}$

also to the loss of imidazole molecules from the composites. The imidazole molecules in cellulose composites differ as to the way of hydrogen bonding to the cellulose: some of them are directly attached to the $\mathrm{OH}-$ groups of cellulose chains and the others through water molecules. Such a bonding of Im was proved in the microcrystalline Cell-Im composites by the solidstate NMR methods (Zhao et al. 2016). In favor of such interpretation are also the following results: the increase in the peak intensity at $150{ }^{\circ} \mathrm{C}$ with increasing of Im content in the sample and the dc conductivity data presented in the next paragraph.

Figure 3 shows DSC thermogram of NCC-Im film in comparison to that of pure NCC film. The data confirmed the results obtained by TGA. They were obtained during two heating cycles performed for each
Table 2 The onset and endset temperatures, max temperature of the process and weight loss for all nanocomposites

\begin{tabular}{|c|c|c|c|}
\hline \multicolumn{4}{|l|}{$\mathrm{NCC}$} \\
\hline & $\mathrm{I}$ & II & III \\
\hline$\Delta \mathrm{Y}(\%)$ & 1.727 & 11.977 & 46.606 \\
\hline Onset $\left({ }^{\circ} \mathrm{C}\right)$ & 206.01 & 248.68 & 331.80 \\
\hline Endset $\left({ }^{\circ} \mathrm{C}\right)$ & 214.33 & 272.56 & 367.72 \\
\hline $\mathrm{T}\left({ }^{\circ} \mathrm{C}\right)$ & 212.79 & 266.11 & 353.71 \\
\hline \multicolumn{4}{|l|}{ 5NCC-Im } \\
\hline & $\mathrm{I}$ & II & III \\
\hline$\Delta \mathrm{Y}(\%)$ & 2.421 & 15.910 & 42.523 \\
\hline Onset $\left({ }^{\circ} \mathrm{C}\right)$ & 63.64 & 194.370 & 310.78 \\
\hline Endset $\left({ }^{\circ} \mathrm{C}\right)$ & 112.95 & 248.29 & 357.71 \\
\hline $\mathrm{T}\left({ }^{\circ} \mathrm{C}\right)$ & 85.98 & 227.60 & 340.32 \\
\hline \multicolumn{4}{|l|}{ 3.8NCC-Im } \\
\hline & \multicolumn{2}{|c|}{ I } & II \\
\hline$\Delta \mathrm{Y}(\%)$ & \multicolumn{2}{|c|}{23.679} & 39.974 \\
\hline Onset $\left({ }^{\circ} \mathrm{C}\right)$ & \multicolumn{2}{|c|}{194.15} & 32.04 \\
\hline Endset $\left({ }^{\circ} \mathrm{C}\right)$ & \multicolumn{2}{|c|}{246.18} & 363.69 \\
\hline $\mathrm{T}\left({ }^{\circ} \mathrm{C}\right)$ & \multicolumn{2}{|c|}{221.28} & 347.99 \\
\hline \multicolumn{4}{|l|}{ 1.7NCC-Im } \\
\hline & I & II & III \\
\hline$\Delta \mathrm{Y}(\%)$ & 8.54 & 19.179 & 37.994 \\
\hline Onset $\left({ }^{\circ} \mathrm{C}\right)$ & 127.08 & 203. 08 & 319.21 \\
\hline Endset $\left({ }^{\circ} \mathrm{C}\right)$ & 163.72 & 247.48 & 363.96 \\
\hline $\mathrm{T}\left({ }^{\circ} \mathrm{C}\right)$ & 149.13 & 223.58 & 348.01 \\
\hline
\end{tabular}

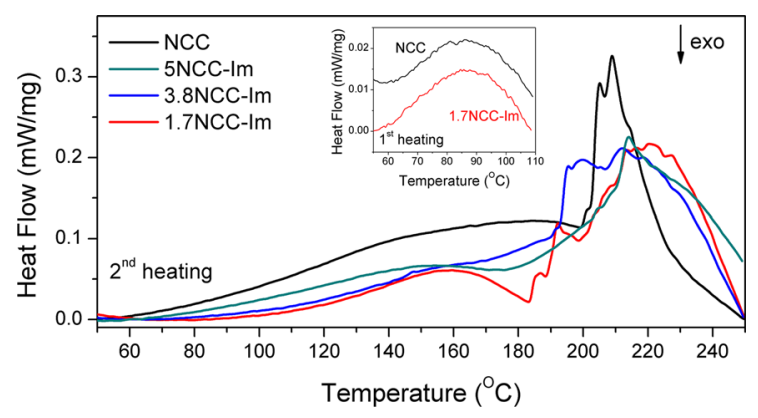

Fig. 3 DSC thermograms of NCC-Im films in comparison to that of pure NCC film obtained during the second heating cycle performed in the temperature range $50-250{ }^{\circ} \mathrm{C}$. The insert shows the endothermic peak observed for 1.7NCC-Im and NCC during the first heating run 
sample. During the first run the samples were heated from 5 to $110{ }^{\circ} \mathrm{C}$ kept at this temperature for about $20 \mathrm{~min}$ and then cooled down to $5{ }^{\circ} \mathrm{C}$. The endothermic peak observed during the first heating cycle for all NCC-Im composites and NCC is attributed to the evaporation of absorbed humidity and weakly bonded water. The examplary peaks obtained for $1.7 \mathrm{NCC}-\mathrm{Im}$ and NCC are given in the insert in Fig. 3. The second heating run was performed in the temperature range $5-250{ }^{\circ} \mathrm{C}$. The DSC thermogram of NCC shows a superposition of two endothermic peaks: a broad one with a low amplitude and a narrow one with a maximum value at about $210{ }^{\circ} \mathrm{C}$. The former peak, as in the DTG thermograms, can be assigned to the evaporation of the strongly bonded water, while the latter one (not observed for the NCC powder) is related to the decomposition of the film. For NCC-Im composites, the second heating cycle revealed also an endothermic broad peak with a low amplitude which for 1.7NCC-Im had a well-marked maximum at about $155{ }^{\circ} \mathrm{C}$. We assigned this peak to the strongly bonded water and also to the beginning of the loss of Im molecules from the composites. The endothermic peak appearing for NCC-Im samples in the temperature range $180-250{ }^{\circ} \mathrm{C}$ is a superposition of two peaks associated with the decomposition of the nanocellulose film, as for pure NCC, and with the loss of imidazole molecules from NCC-Im.

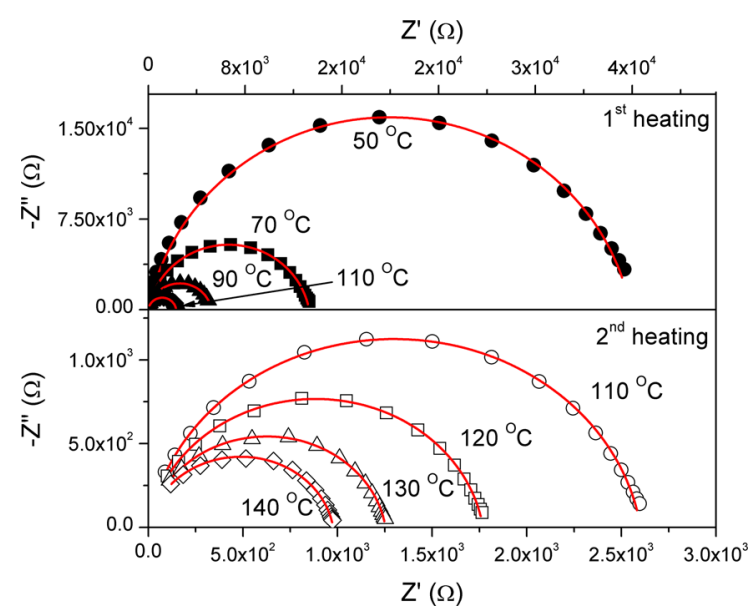

Fig. 4 Nyquist plots for 1.7NCC-Im at selected temperatures during the first heating (upper plots), and during the second heating (lower plots). Solids lines represent the best fit of Eq. 1 to the experimental points with the parameters given in Table 3
Table 3 The values of the parameters resulting from the fitting of Eq. 1 to the experimental points shown in Fig. 4 for 1.7NCC-Im

\begin{tabular}{llrll}
\hline $\begin{array}{l}\text { Temperature } \\
\left({ }^{\circ} \mathrm{C}\right)\end{array}$ & Heating cycle & $\mathrm{R}_{\mathrm{dc}}(\Omega)$ & $\mathrm{C}(\mathrm{pF})$ & $\alpha$ \\
\hline 50 & $1 \mathrm{st}$ & $38,238.9$ & 49.5 & 0.88 \\
70 & $1 \mathrm{st}$ & $12,738.7$ & 49.5 & 0.89 \\
90 & $1 \mathrm{st}$ & 4995.7 & 47.2 & 0.91 \\
110 & $1 \mathrm{st}$ & 2200.4 & 48.9 & 0.93 \\
110 & 2nd & 2601.0 & 54.0 & 0.91 \\
120 & 2nd & 1767.8 & 54.9 & 0.91 \\
130 & 2nd & 1253.6 & 55.9 & 0.91 \\
140 & 2nd & 976.3 & 57.1 & 0.91 \\
\hline
\end{tabular}

Electrical conductivity

The impedance spectroscopy measurements were performed to investigate the temperature behavior of the electrical conductivity of NCC and NCC-Im films. The analysis of the results showed that in the frequency window from $1 \mathrm{~Hz}$ to $10 \mathrm{MHz}$ the response of all nanocomposites in the studied temperature range is composed of one semicircle. Therefore, the experimental data were analyzed on the basis of the wellknown Cole equation (Cole et al. 1941).

$Z^{*}(\omega)=Z^{\prime}(\omega)+i Z^{\prime \prime}(\omega)=\frac{R_{d c}}{1+(i \omega \tau)^{\alpha}}$

where $Z^{*}(\omega)$ is the complex impedance at angular frequency $\omega$ ( $\omega=2 \pi f$, where $f$ is the linear frequency of the probing electric filed), $Z^{\prime}(\omega)$ and $Z^{\prime \prime}(\omega)$ is the real and imaginary part of $Z^{*}(\omega), R_{d c}$ is the $d c$ resistance of the sample, $\tau=2 \pi R C$ is the characteristic time constant ( $C$ denotes the electric capacity), $\alpha$ is an empirical exponent $(0<\alpha \leq 1)$. Exemplary impedance spectra in the form of the Nyquist plots ( $-\mathrm{Z}^{\prime}$ vs Z') obtained for NCC doped with the highest amount of Im, 1.7NCC-Im, are shown for selected temperatures in Fig. 4.

The upper plot presents the data obtained during the first heating run and the lower one during the second heating run. The Nyquist plots presented in Fig. 4, but also for other nanocomposites and temperatures studied, can be estimated as single semicircles and thus they were fitted with Eq. 1. The solid lines in Fig. 4 represent the best fit of Eq. 1 to the experimental points with the parameters given in Table 3 . Knowing the sample dimension (its surface area A 

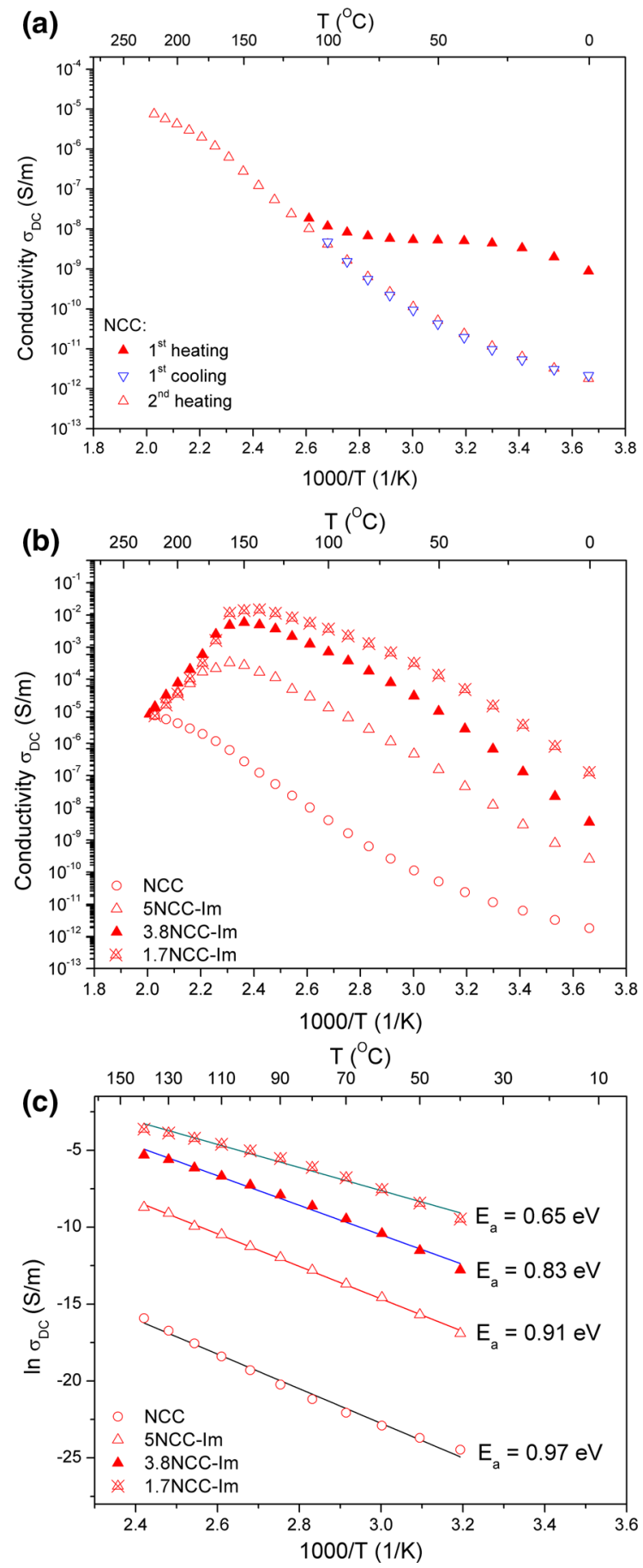

and thickness d) the bulk dc conductivity, $\sigma_{\mathrm{dc}}$, can be evaluated from the formula: $\sigma_{\mathrm{dc}}=1 / \mathrm{R}_{\mathrm{dc}}(\mathrm{d} / \mathrm{A})$.

The temperature dependencies of $\sigma_{\mathrm{dc}}\left(\log \sigma_{\mathrm{dc}}(1 / \mathrm{T})\right)$ obtained in this way for NCC and NCC-Im films are shown in Fig. 5a, b, respectively. The conductivity for
4Fig. 5 The de conductivity $v s$ inverse temperature for pure NCC film collected on two heating runs and one cooling cycle (a), The dc conductivity $v s$ inverse temperature for 5NCC-Im, 3.8NCC-Im, and 1.7NCC-Im films obtained during second heating cycles together with data for pure NCC film, for comparison (b), Arrhenius plots of the dc conductivity with activation energies for NCC-Im with variable concentration of Im and for pure NCC nanocomposite. The solid lines are the best fits to the Arrhenius model (Eq. 2)

all samples studied was determined during first heating cycle performed in the temperature range from 0 to $110{ }^{\circ} \mathrm{C}$, next during cooling of the sample to $0{ }^{\circ} \mathrm{C}$ and again during heating cycles performed in the range from 0 to $220^{\circ} \mathrm{C}$. Figure $5 \mathrm{a}$ shows the data obtained for NCC in a whole heating and cooling cycle. The conductivity in the first heating run is associated with a mobility of water presented in the film. Protons of water molecules acted as conducting species.

The conductivity measured during cooling of the sample exactly matches the corresponding values of that obtained during the second heating run up to $110^{\circ} \mathrm{C}$. It means that the first heating of the sample up to $110{ }^{\circ} \mathrm{C}$ results in the evaporation of water and $\sigma_{\mathrm{dc}}$ measured is associated with much less mobile protons of hydroxyl groups of nanocrystalline cellulose, which results in a lower value of conductivity as compared to the values obtained during the first heating run. Above $110{ }^{\circ} \mathrm{C}$ an additional contribution to $\sigma_{\mathrm{dc}}$ i.e. the segmental motions of the polymer chains, starts to play a role and leads to the observed increase in conductivity (Smolarkiewicz et al. 2016). However, the conductivity in a pure NCC increases only up to $10^{-5} \mathrm{~S} / \mathrm{m}$ above $200{ }^{\circ} \mathrm{C}$ which gives a relatively low value.

Figure $5 \mathrm{~b}$ shows the $\log \sigma_{\mathrm{dc}}(1 / \mathrm{T})$ plots for $5 \mathrm{NCC}$ Im, 3.8NCC-Im, 1.7NCC-Im, and NCC, for comparison, but only for the results obtained on the second heating cycle. For all films, the conductivity increases with increasing temperature. This is a typical behavior in proton conductors. Moreover, the increase in conductivity of NCC-Im as a function of imidazole concentration is easily seen. The conductivity is equal to $3.3 \times 10^{-4}, 5.8 \times 10^{-3}$, and $2.7 \times 10^{-2} \mathrm{~S} / \mathrm{m}$ for 5NCC-Im, 3.8NCC-Im, and 1.7NCC-Im, respectively. The maximum of conductivity obtained for 1.7NCCIm is about five orders of magnitude higher than that of pure NCC at this same temperature. The increase in conductivity values with increasing content of 
imidazole molecules in nanocomposites is an evidence that the protons from the imidazole molecules are the conducting species, similarly to the situation in the composites of microcrystalline Cell-Im (Zhao et al. 2016). The $\sigma_{\mathrm{dc}}$, in all NCC-Im composites, after reaching the maximum at about $150{ }^{\circ} \mathrm{C}$, starts to decrease and finally reaches the same level as for pure NCC film. The observed effect is due to the decomposition of the nanocomposites caused by the disruption of the hydrogen bond networks involving the imidazole molecules. As a result, the Im molecules are no more involved in conductivity. The $\sigma_{\mathrm{dc}}$ data confirm our interpretation of DTG and DSC results. Although the nanocomposites doped with imidazole start to decompose at temperatures lower than that of pure NCC they are still thermally stable under higher temperature than the standard operating temperature of PEM.

The conductivity of all films studied increased linearly in the temperature range from 35 to $140{ }^{\circ} \mathrm{C}$ (Fig. 5c) therefore, the experimental data were fitted with the Arrhenius equation to determine the activation energy for proton transport:

$\sigma(T)=\sigma_{0} \exp \left(-E_{a} / k T\right)$

where $\sigma_{0}$ is the pre-exponential factor, $E_{\mathrm{a}}$ is the activation energy, $k$ is the Boltzmann constant and $T$ denotes temperature. The best-fit curves are presented in Fig. $5 \mathrm{c}$ as the solid lines. The fitted energy values, $E_{\mathrm{a}}$, are equal to $0.97,0.91,0.83$, and $0.65 \mathrm{eV}$ for pure NCC, $5 \mathrm{NCC}-\mathrm{Im}, 3.8 \mathrm{NCC}-\mathrm{Im}$, and 1.7NCCIm, respectively. In all cases, the estimated error is $\pm 0.01 \mathrm{eV}$. The activation energies for proton conduction in the studied NCC and NCC-Im films are higher than those of cellulose nanofibers and nanocrystals $\left(E_{\mathrm{a}}=0.21\right.$ and $0.24 \mathrm{eV}$, respectively) (Bayer et al. 2016), and Nafion $\left(E_{\mathrm{a}}=0.16 \mathrm{eV}\right)$ (Kreuer et al. 1993). The latter values of activation energies are characteristic of Grotthuss mechanism (Agmon et al. 1995) which dominates at high humidity. The proton conductivity in NCN and CNF was determined at high humidity conditions, while we studied our samples under anhydrous conditions. This fact explains the difference in activation energies. On the other hand, our results coincide with those obtained for the materials measured at lower humidity levels and/or containing heterocyclic molecules (Kreuer et al. 1993; Tang et al. 2014; Pandey et al. 1999; Yamada et al. 2012; Yamada et al. 2004;
Yamada and Ogino 2015). Generally, the higher activation energy (i.e. $0.5-0.9 \mathrm{eV}$ ) reflects other than Grotthuss conduction mechanism like the vehicle (Knauth et al. 2008; Kreuer et al. 1982, 1996) or proton hopping mechanism (Eikerling et al. 2001; Luduena et al. 2011). The latter mechanism was well proved and described for microcrystalline Cell-Im composites (Zhao et al. 2016) in which Im molecules formed a dynamic hydrogen bond network with residual water molecules and hydroxyl groups of cellulose chains. The proton transport mechanism is supported by molecular reorientation of Im molecules and tautomerism of imidazole molecules which does not take place between imidazole molecules alone, but that it is coupled to proton exchange both with water and cellulose $-\mathrm{OH}$ groups. However, such proton hop along the $\mathrm{OH}$ groups of water or cellulose on the cellulose surface alone does not contribute to the conductivity. It has to be associated with dissociation of imidazole into a "free" solvated imidazole cation and a "free" solvated imidazolate anion. This process requires a high molecular mobility of $\mathrm{OH}$ groups and imidazole molecules as proved by NMR methods for microcrystalline Cell-Im composites (Zhao et al. 2016).

We postulate the same proton conducting mechanism also in the studied NCC-Im for the following reasons: the Im molecules in the nanocomposites, like in microcrystalline composites, were introduced into the cellulose matrix through coating thus, they are bounded to cellulose chains only on the surfaces, and the activation energies for proton conduction in NCCIm (0.91-0.65 eV) and microcrystalline Cell-Im (0.82) are quite similar. Especially, the latter fact indicates that the same proton conduction mechanism dominates in nano- and microcrystalline cellulosedoped imidazole composites. Of course, our assumption requires confirmation and relevant NMR experiments are planned. In Fig. $5 \mathrm{c}$ we can observe that the higher content of imidazole in the nanocomposites leads to a decrease in the activation energy for proton transport. This observation can be explained in the following way: the activation energy of proton transport depends on the distance between hopping sites so, the increase in Im concentration on the cellulose nanocrystals surface results in the shortening of the distance between heterocycles and in the reduction of the proton distance hop between the two neighboring 
sites. Thus, the activation energy of the proton transport is redused.

\section{Conclusion}

The successful synthesis of biodegradable polymeric composite of microcrystalline cellulose doped with imidazole (Smolarkiewicz et al. 2015, 2016; Zhao et al. 2016) was an inspiration for the work presented in this paper. Here, we report on further development of this type of the proton conducting composite but including nanocrystalline cellulose as the matrix support. Starting these studies we have formulated the following research hypotheses: (1) replacement of cellulose raw material by nanocrystalline cellulose will enable more effective functionalization of nanocellulose surface by the heterocycles molecules and consequently will increase the proton conductivity, (2) the application of the heterocyclic nitrogencontaining molecules as conducting species will lead to nanocomposites with proton conductivity in the intermediate temperature range, higher than $100{ }^{\circ} \mathrm{C}$. The results presented positively verified our hypotheses. We obtained 1.7NCC-Im with the highest concentration of imidazole equal to one Im per 1.7 glucose unit compared to one Im per 5 glucose unit for microcrystalline Cell-Im. The 1.7NCC-Im film shows the maximal electrical conductivity equal to $2.7 \times 10^{-2} \mathrm{~S} / \mathrm{m}$ at $140{ }^{\circ} \mathrm{C}$ which is by two orders of magnitude higher than that obtained for microcrystalline Cell-Im $\left(2.0 \times 10^{-4} \mathrm{~S} / \mathrm{m}\right.$ at $\left.160{ }^{\circ} \mathrm{C}\right)$, (Smolarkiewicz et al. 2016). The nanocomposite is thermally stable well above $100{ }^{\circ} \mathrm{C}$ and the important feature is that it shows conductivity under anhydrous conditions. Thus, nanocrystalline cellulose doped with imidazole is a promising material for a possible application as a membrane in fuel cells in which the proton conductivity increases up to $140{ }^{\circ} \mathrm{C}$. Earlier, increases in proton conductivity in nanocellulose membranes up to $120{ }^{\circ} \mathrm{C}$ have been reported under strong humidification (Bayer et al. 2016).

\section{Compliance with ethical standards}

Conflict of interests The authors declare that they have no conflict of interest.

Open Access This article is distributed under the terms of the Creative Commons Attribution 4.0 International License (http:// creativecommons.org/licenses/by/4.0/), which permits unrestricted use, distribution, and reproduction in any medium, provided you give appropriate credit to the original author(s) and the source, provide a link to the Creative Commons license, and indicate if changes were made.

\section{References}

Agmon N (1995) The Grotthuss mechanism. Chem Phys Lett 244:456-462

Anglès MN, Dufresne A (2000) Plasticized starch/tunicin whiskers nanocomposites. 1. Structural analysis. Macromolecules 33:8344-8353

Bayer T, Cunning BV, Selyanchyn R, Nishihara M, Fujikawa S, Sasaki K, Lyth SM (2016) High temperature proton conduction in nanocellulose membranes: paper fuel cells. Chem Mater 28:4805-4814

Borjesson M, Westman G (2015) Crystalline nanocellulosepreparation, modification and properties, cellulose-fundamental aspects and current trends. InTech, Rijeka. https://doi.org/10.5772/61899

Celik SÜ, Bozkurt A, Hosseini SS (2012) Alternatives toward proton conductive anhydrous membranes for fuel cells: heterocyclic protogenic solvents comprising polymer electrolytes. Prog Polym Sci 37:1265-1291

Cole K, Cole R (1941) Dispersion an absorption in dielectrics. J Chem Phys 9:341-345

Curtin DE, Lousenberg RD, Henry TJ, Tangeman PC, Tisack ME (2004) Advanced materials for improved PEMFC performance and life. J Power Sour 131:41-48

Devanathan R (2008) Recent developments in proton exchange membranes for fuel cells. Energy Environ Sci 1:101-119

Dufresne A (2013) Nanocellulose: a new ageless bionanomaterial. Mat Today 16:220-227

Eikerling M, Kornyshev AA, Kuznetsov AM, Ulstrup J, Walbran S (2001) Mechanism of proton conductance in polymer electrolyte membranes. J Phys Chem B 105:3646-3662

Gasteiger HA, Kocha SS, Sompalli B, Wagner FT (2005) Activity benchmarks and requirements for Pt, Pt-alloy, and non-Pt oxygen reduction catalysts for PEMFCs. Appl Catal B 56:9-35

Gierke T, Munn G, Wilson F (1981) The morphology in nafion perfluorinated membrane products, as determined by wideand small-angle X-ray studies. J Polym Sci Polym Phys Ed 19:1687-1704

Hu Y, Li X, Yan L, Yue B (2017) Improving the overall characteristics of proton exchange membranes via nanophase separation technologies: a progress review. Fuel Cells 17:3-17

Knauth P, Schoonman J (2008) Nanocomposites: ionic conducting materials and structural spectroscopies. Springer, Berlin

Kreuer KD (1996) Proton conductivity. Chem Mater 8:610-641

Kreuer KD (1997) On the development of proton conducting materials for technological applications. Solid State Ion 97:1-15

Kreuer KD, Rabenau A, Weppner W (1982) Vehicle mechanism, a new model for the interpretation of the conductivity 
of fast proton conductors. Angew Chem Int Ed Engl 8:610-641

Kreuer KD, Dippel T, Meyer W, Maier J (1993) Nafion membranes: molecular diffusion, proton conductivity and proton conduction mechanism. Mat Res Soc Symp Proc 293:273-282

Kreuer KD, Fuchs A, Ise M, Spaeth M, Maier J (1998) Imidazole and pyrazole-based proton conducting polymers and liquids. Electrochim Acta 43:1281-1288

Li Q, Jensen JO, Savinell RF, Bjerrum NJ (2009) High temperature proton exchange membranes based on polybenzimidazoles for fuel cells. Prog Polym Sci 34:449-477

Luduena GA, Kuhne TD, Sebastiani D (2011) Mixed grotthuss and vehicle transport mechanism in proton conducting polymers from $\mathrm{Ab}$ initio molecular dynamics simulation. Chem Mater 23:1421-4123

Mariano M, Dufresne A, Kissi NE (2014) Cellulose nanocrystals and related nanocomposites: review of some properties and challenges. Polym Sci Part B Polym Phys 52:791-806

Mauritz KA, Moore RB (2004) State of understanding of Nafion. Chem Rev 104:4535-4585

Miao C, Hamad WY (2013) Cellulose reinforced polymer composites and nanocomposites: a critical review. Cellulose 20:2221-2262

Moon RJ, Martini A, Nairn J, Simonsen J, Youngblood J (2011) Cellulose nanomaterials review: structure, properties and nanocomposites. Chem Soc Rev 40:3941-3994

O'Sullivan AC (1997) Cellulose: structure slowly unravels. Cellulose 4:173-207

Pandey K, Lakshmi N (1999) Evidence of hopping model of ionic conductivity in phosphomolybdic acid studied by a.c. conductivity measurements. J Mater Sci 34:1749-1752

Pandey JK, Takagi H, Nakagaito AN, Saini DR, Ahn SH (2012) An overview on the cellulose based conducting composites. Compostes Part B 43:2822-2826

Peng BL, Dhar N, Liu HL, Tam KC (2011) Chemistry and applications of nanocrystalline cellulose and its derivatives: a nanotechnology perspective. Can J Chem Eng 89:1191-1206

Savinell R, Yeager E, Tryk D, Landau U, Wainright J, Weng J, Lux K, Litt M, Rogers C (1994) A polymer electrolyte for operation at temperatures up to $200 \& \# \mathrm{AB} 0$;C. Electrochem Soc 141:46-48

Schuster MFH, Meyer WH (2003) Anhydrous proton-conducting polymers. Ann Rev Mater Reson 33:233-261

Scott K, Xu C, Wu X (2014) Intermediate temperature protonconducting membrane electrolytes for fuel cells. WENE. https://doi.org/10.1002/wene.64
Sharaf OZ, Orhan MF (2013) An overview of fuel cell technology: fundamentals and applications. Renew Sust Energy Rev 32:810-853

Siqueira G, Bras J, Dufresne A (2010) Cellulosic bionanocomposites: a review of preparation, properties and applications. Polymers 2:728-765

Smolarkiewicz I, Rachocki A, Pogorzelec-Glaser K, Pankiewicz R, Ławniczak P, Łapiński A, Jarek M, Tritt-Goc J (2015) Proton-conducting microcrystalline cellulose doped with imidazole. Thermal and electrical properties. Electrochim Acta 155:38-44

Smolarkiewicz I, Rachocki A, Pogorzelec-Glaser K, Pankiewicz R, Ławniczak P, Tritt-Goc J (2016) Effect of surface coating of microcrystalline cellulose by imidazole molecules on proton conductivity. Eur Polym J 78:186-194

Song S, Tsiakaras P (2006) Recent progress in direct ethanol proton exchange membrane fuel cells (DE-PEMFCs). Appl Catal B 63:187-193

Szcześniak L, Rachocki A, Tritt-Goc J (2008) Glass Transition temperature and thermal decomposition of cellulose powder. Cellulose 15:445-451

Tang Q, Liu Y, Liu S, He D, Miao J, Wang X, Yang G, Shi Z, Zheng Z (2014) High proton conductin at above $100 \&$ \#xB0;C mediated by hydrogen bonding in lanthanide metal-organic framework. J Am Chem Soc 136:12444-12449

Xing B, Savadogo O (2000) Hydrogen/oxygen polymer electrolyte membrane fuel cells (PEMFCs) based on alkalinedoped polybenzimidazole (PBI). Electrochem Commun 2:697-702

Yamada M, Goto A (2012) Proton conduction of DNA-imidazole composite material under anhydrous condition. Polym J 44:415-420

Yamada M, Honma I (2004) A biopolymer composite material as an anhydrous proton-conducting membrane. Angew Chem Int Ed 43:3688-3691

Yamada M, Ogino T (2015) Anhydrous proton conductor consisting of pectin-inorganic composite material. J Appl Polym Sci 132(42433):1-7

Zhang Y, Li J, Ma L, Cai W, Cheng H (2015) Recent developments on alternative exchange membranes: strategies for systematic performance improvement. Energy Technol 3:675-691

Zhao L, Smolarkiewicz I, Limbach HH, Breitzke H, PogorzelecGlaser K, Pankiewicz R, Tritt-Goc J, Gutmann T, Buntkowsky G (2016) Imidazole-doped cellulose as membrane for fuel cells: structural and dynamic insights from solidstate NMR. J Phys Chem C 120:19574-19585 